\title{
Dose-response relations between Purpureocillium lilacinum PLSAU-1 and Meloidogyne incognita infecting brinjal plant on plant growth and nematode management: a greenhouse study
}

\author{
Most. Sinthia Sarven', F. M. Aminuzzaman ${ }^{2}$ and Md. Enamul Huq ${ }^{3 *}$
}

\begin{abstract}
The efficacy of various doses of Purpureocillium lilacinum PLSAU-1 (P. lilacinum PLSAU-1) was evaluated against brinjal root-knot pathogen, Meloidogyne incognita (M. incognita) at different inoculum levels. Experimental pot soil was treated by four doses $\left(0,1 \times 10^{5}, 5 \times 10^{5}\right.$, and $1 \times 10^{6} \mathrm{CFU} / \mathrm{g}$ soil) of $P$. lilacinum PLSAU- 1 before transplanting, and 5 inoculum levels of $M$. incognita $\left(0,100,400,800,1600\right.$, and 3200 eggs per $100 \mathrm{~cm}^{3}$ soil) were used after 3 days of brinjal transplantation. A significant correlation was observed between doses of $P$. lilacinum PLSAU-1 and inoculum densities of $M$. incognita. Among the doses, the rate of P. lilacinum PLSAU-1 of $1 \times 10^{6} \mathrm{CFU} / \mathrm{g}$ soil enhanced highly plant growth parameters. Inoculation of $M$. incognita reduced plant growth significantly, and the reduction increased with the increase of inoculum density of $M$. incognita. The application of P. lilacinum PLSAU- 1 at $1 \times 10^{6} \mathrm{CFU} / \mathrm{g}$ soil reduced a maximum of $72 \%$ gall index and $84 \%$ egg masses when the crop was challenged by 800 and 400 eggs $/ 100 \mathrm{~cm}^{3}$ soil, respectively. The dose of $1 \times 10^{6}$ CFU/g soil of $P$. lilacinum PLSAU-1 showed effectiveness to reduce reproduction factor of $M$. incognita up to $81 \%$ when the crop was inoculated by 800 eggs of the pest $/ 100 \mathrm{~cm}^{3}$ soil. The study demonstrated that $P$. lilacinum PLSAU-1 is an effective bio-agent for controlling of root-knot nematode on brinjal and can be a key component of environment-friendly management approach.
\end{abstract}

Keywords: Purpureocillium lilacinum PLSAU-1, Biological control, Meloidogyne incognita, Inoculum density, Brinjal

\section{Background}

Brinjal (Solanum melongena L.) is a very common, popular, and second most (next to potato) important vegetable crop, in Bangladesh and other parts of the world, in respect of acreage and production. It contains higher calorie, iron, phosphorus, and riboflavin than tomato (Meherunnahar and Paul 2009).

The incidence of insect pests and diseases generally hampered the production of eggplant. In Bangladesh,

\footnotetext{
* Correspondence: enamul_huq@whu.edu.cn

${ }^{3}$ State Key Laboratory of Information Engineering in Surveying, Mapping and Remote Sensing, Wuhan University, 129 Luoyu Road, Wuhan 430079, Hubei, China

Full list of author information is available at the end of the article
}

this crop suffers from 13 different diseases, recorded (Rashid 2000). Among those, root knot has been considered as one of the key constrains in eggplant cultivation. It is caused by Melodoigyne spp., the widely distributed in all eggplant-growing areas of Bangladesh with moderate incidence (27.2\%) (Bari 2001) as well as in other countries of the world. Meloidogyne incognita (M. incognita) is the most vicious species among them, which causes severe harms to a quantity of economically significant agriculture and greenhouse crops (Huang et al. 2014).

Infection of roots by nematodes affects uptake of water and nutrients and interferes with the translocation of minerals and photosynthates, which change the shoot 
to root ratio (Saikia et al. 2013) and expose the plants to other pathogen infection. For example, nematode root infection increases the incidence and severity of wilt and root rot diseases on a variety of crops, which can negatively influence yield (Osman et al. 2018). Controlling of this type of plant-parasitic nematode is essential for effective crop production. Presently, the most proficient chemical nematicides (e.g., methyl bromide) have been constrained due to their hazardous effect on animal and human. Therefore, it has led to an immense interest in biological control in order to achieve an environmentally safe method of reducing nematode damage (Abdelnabby et al. 2011).

Purpureocillium lilacinum is one of the most promising and practicable biocontrol agents for the management of plant parasite nematodes (Yang et al. 2015b). Previous studies indicated that this fungus adapts well in varied climatic conditions and is much effective in controlling root-knot nematodes. This fungus is capable of infecting all life stages of the root-knot nematode. The production of leucinotoxins, chitinases, proteases, and acetic acid by P. lilacinum is associated with the infection process (Yang et al. 2015b). Although $P$. lilacinum has been reported as a nematode biocontrol agent on plant crops (Usman and Siddiqui 2012 and Yang et al. 2015b), and recently, it also has been reported as a biocontrol agent for controlling Sclerotinia sclerotiorum the rot on oilseed rape (Yang et al. 2015a).

Recently, some works have been done on the effect of fungal strains for the management of root-knot nematode on tomato and cucumber (Kiewnick et al. 2011 and Huang et al. 2014). However, the dose-response relationship and optimum dose for controlling of root knot $(M$. incognita) on brinjal still remain unidentified.

The main objective of this study was to evaluate the dose effect of P. lilacinum PLSAU-1 on the plant growth parameters, root galling at different inoculum level of nematode, and nematode population and reproduction factor of the root-knot nematode $M$. incognita at different inoculum levels in brinjal.

\section{Material and methods}

\section{Experimental materials and design}

The experimental soil was silty loam (13.8\% clay, $56.5 \%$ silt, and $29.7 \%$ sand) with a $\mathrm{pH}$ of 5.2 and an organic matter content of $1.5 \%$. Required soil, sand, and decomposed cow-dung were mixed properly in a ratio of 6:2:1. The mixture was autoclaved at $121^{\circ} \mathrm{C}$ for $15 \mathrm{~min}$ at 15 PSI. Plastic pots of $1000 \mathrm{~cm}^{3}$ were cleaned, washed, dried up properly, and sterilized with 70\% ethanol. Then, they were filled with $800 \mathrm{~g}$ soil and arranged according to the experimental design. The experiment was laid out in two factors according to a randomized complete block design (RCBD) having eight replications for each treatment.

\section{Inoculums and fungus preparation}

Nematode samples ( $M$. incognita) were collected from nematode-infected brinjal roots. Egg masses were picked up and inoculated in young seedlings of brinjal. Sub-culturing was done subsequently by inoculating new brinjal seedling with egg masses. Galled roots of tomato, eggplant, cucumber, and bottle gourd were collected from farmers' field of different districts (Dinajpur, Narayangonj, Mymensingh, Jessore, and Dhaka) in Bangladesh. The samples were kept in double-layered plastic bags at $48^{\circ} \mathrm{C}$, and fungi were isolated within 1 month. After collection, roots were washed by running tap water and placed under a dissecting microscope. Egg masses were picked up manually, using dissecting forceps, and the roots were dissected beneath the egg masses; females were carefully picked up with a dissecting needle. Eggs were extracted from the egg masses, following the method of Hussey and Barker (1973). Egg masses were treated by $1 \% \mathrm{NaOCl}$ solution for 1 min to release eggs from the egg masses and disinfect the egg surface, whereas females were treated by $0.5 \% \mathrm{NaOCl}$ solution for $3 \mathrm{~min}$. Treated eggs and females were rinsed by a sterile distilled water to remove residual $\mathrm{NaOCl}$. One hundred eggs (ca.) were plated and smeared on each potato dextrose agar (PDA) plate; five plates were applied for each sample. Five females were crushed by a sterile forceps and smeared on each PDA plate. All plates were incubated at $25^{\circ} \mathrm{C}$ for 5 days. The incubated plates were daily examined under an inverted microscope, and hyphae grown from eggs or females' fragments were transferred on to PDA plates for purification and identification. The isolates were identified, following the standard keys of Houbraken et al. (2010). This fungus was isolated at the laboratory of Department of Plant Pathology, Sher-e-Bangla Agricultural University, Dhaka, Bangladesh. The fungus was named as P. lilacinum PLSAU-1 (Aminuzzaman et al. 2018).

\section{Inoculation of $P$. lilacinum PLSAU-1 and $M$. incognita}

P. lilacinum PLSAU-1 spores were mixed carefully into the soil at $\left(1 \times 10^{5}, 5 \times 10^{5}\right.$, and $\left.1 \times 10^{6} \mathrm{CFU}\right)$ of P. lilacinum PLSAU-1/g of soil in defined pots with a micropipette. Four-week-old seedlings were uprooted cautiously from the plastic trays and transplanted in the fungal-treated pots. Sufficient water was given just after transplantation. Then, after 3 days, nematode was inoculated at $\left(0,400,800,1600\right.$, and $\left.3200 \mathrm{eggs} / 100 \mathrm{~cm}^{3}\right)$ of pot soil. Four holes (2-cm depth) around the plants were made with the help of metallic rod, and egg suspension was inoculated into the holes by a micropipette. Pot soil contained water only untreated control and nematode 
only inoculated control. General sanitation was maintained throughout the growing period.

\section{Data recording and analyzing}

Plants were harvested after 2 months for collecting data. The shoot length was measured from the base of the plant to the growing point of the youngest leaf. To measure root length, the roots were cleaned gently by water and the length was measured from the growing point of the root to the longest available lateral root apex with measuring tape. After taking root length and fresh weight, nematode infection was determined by rating root galling based on the $0-10$ scale $(0=$ no galls and $10=$ dead plant) (Bridge and Page 1980). The number of egg mass/root system was counted by Hartman and Sasser (1985). The roots were soaked in Phloxine-B ( $2 \mathrm{mg} / \mathrm{l})$ solution for $15 \mathrm{~min}$, and then, the egg masses/ roots were counted using a magnifying lens. The extraction of J2 from the soil and root was done, using a Whitehead and Hemming tray method (Whitehead and Hemming 1965). Pot soil was mixed thoroughly, and a $10-\mathrm{g}$ soil from each pot was weighted and placed on a sieve on a bowl filled with water. The upper portion of the sieve was lined by three layers of kitchen tissue paper. After 3 days, the bowl water was collected in a beaker, and then, nematodes were concentrated into 10 $\mathrm{ml}$ of water using 500 mesh sieves. The two-milliliter suspension was taken from each sample and placed into a counting dish, and the $\mathrm{J} 2$ were counted under a compound microscope. To estimate the eggs per root, roots were gently washed by tap water to remove soil. Then, roots were chopped into $2 \mathrm{~cm}$ lengths placed in a $100 \mathrm{ml}$ solution of $0.6 \%$ sodium hypochlorite and mixed, using an electric blender. The blended mixture was poured through the sieves from top to bottom $(80,200$, and 500 meshes). Eggs were collected from 500 mesh sieve in a beaker and counted using a counting chamber.

For the percentage of egg mass colonization, five egg masses/plant were randomly collected from the eggplant roots, washed by a sterile water, and disinfected by a solution of Clorox rinsed with water and placed on a PDA plate. The number of colonized egg masses was determined after 5 days of incubation at $25^{\circ} \mathrm{C}$. The presence of $P$. lilacinum PLSAU-1 into egg mass of $M$. incognita was confirmed by preparation of slides from the culture grown on PDA. Soil colonization by $P$. lilacinum PLSAU-1 (CFU/g soil) was determined by a soil dilution plate technique. In details, $2 \mathrm{~g}$ of soil (wet weight) was transferred to flasks containing $20 \mathrm{ml}$ of sterile demineralized water and shake on a horizontal shaker for $25 \mathrm{~min}$ at $170 \mathrm{rpm}$. After preparation of the serial dilutions, CFU numbers were determined by plating onto OHIO agar (Johnson and Curl 1972). Final nematode population was determined eggs per root plus the 2nd-stage juvenile per pot; reproduction factor $=($ final nematode population)/(initial nematode population).

The recorded data of various parameters were statistically analyzed using MSTAT-C statistical package program. Differences among treatment means were determined by Duncan's new multiple range test (DMRT).

\section{Results and discussion \\ Effect of P. lilacinum PLSAU-1 and $M$. incognita application rates on plant growth parameters and nematode's population}

Results of the present study indicate significant effects of inoculum level and dose applied on the growth parameters. The treated $1 \times 10^{5}, 5 \times 10^{5}$, and $1 \times 10^{6} \mathrm{CFU} / \mathrm{g}$ soil of P. lilacinum PLSAU-1 shoot fresh weight and shoot length were significantly greater than the untreated control (Table 1). The mechanism of improvement of plant growth by the biocontrol fungi is unknown. Our hypothesis is maybe it enhanced nutrient uptake, incorporate mineral nutrition through mineral solubilization, disease suppression, or involved production of phytohormones. Also, it may be caused when this bio-agent parasitizes other pathogenic fungi and competes with harmful plant microorganisms (Contreras-Cornejo et al. 2009).

For the inoculum level, shoot fresh weight and shoot length were significantly reduced than the un-inoculated control and the reduction increased with the increase of inoculum's density. Due to the application of P. lilacinum PLSAU-1, the root length increased than the untreated control and the increased trend was along with increased dose. The highest dose of $1 \times 10^{6} \mathrm{CFU} / \mathrm{g}$ soil showed the highest root length, where the other two doses showed similar statistical results. Conversely, a significant reduction of root length was found at all inoculated treatments of $M$. incognita compared to the un-inoculated one. In the case of root fresh weight, the highest dose $\left(1 \times 10^{6} \mathrm{CFU} / \mathrm{g}\right.$ soil $)$ showed the highest root fresh weight. All the tested inoculum levels showed a significant reduction in root fresh weight than the control. The greater decline of plant growth parameters coupled with an elevated rate of nematode development might be due to the more rapid invasion of roots by larger numbers of $\mathrm{J} 2$ and the consequent maturity of adult females. This is possible as the developing giant cell systems and disturbance of the developing xylem lead to change in physiological functions such as nutrient uptake, translocation of nutrients and water from root to plant, and subsequent photosynthesis (Davis et al. 2003).

Obtained results also indicated that the plant growth parameters roughly affected by inoculum density of $M$. incognita as they decreased with increasing the nematode population. As well, lower plant growth characters were observed when the plants were inoculated by 1600 


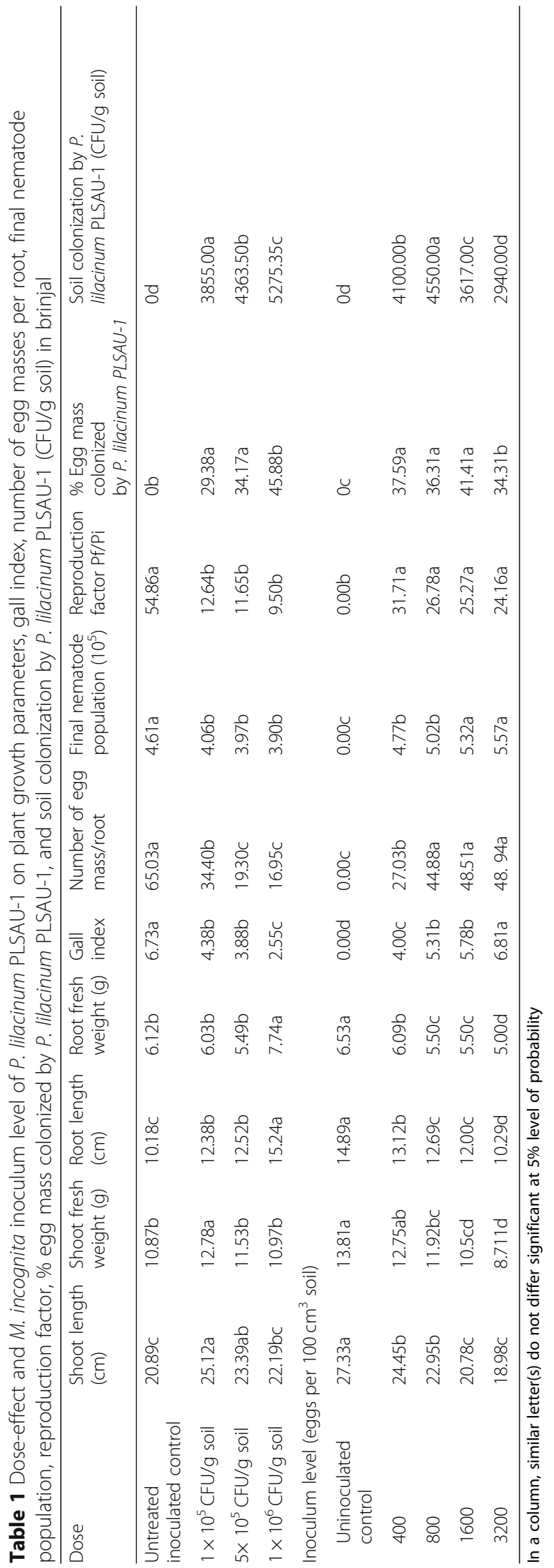


and 3200 eggs per $100 \mathrm{~g}$ soil. Charegani et al. (2012) reported similar results as the inoculation of tomato with inoculum level (40 eggs and J2) of $M$. incognita or $M$. javanica per gram of soil reduced shoot length and fresh dry weights markedly, and the reduction was significantly correlated to its inoculum density.

The analytical results showed that all the tested doses of P. lilacinum PLSAU-1 caused significant reductions in gall index rating, number of egg masses per root system, final nematode population, and reproduction factor compared to untreated control (0 CFU/g soil). The highest reduction was observed for the highest $\left(1 \times 10^{6} \mathrm{CFU} /\right.$ $\mathrm{g}$ soil) dose of bio-agent. In contrast, all the inoculum densities increased the gall index rating and number of egg masses per root system than the un-inoculated control. Inoculating soil with (3200 eggs per $100 \mathrm{~cm}^{3}$ soil) led to a highest gall index development and a number of egg masses per root system. The final nematode population increased with the increase of inoculum level. The highest reproduction factor was observed when the soil was inoculated by $400 \mathrm{eggs} / 100 \mathrm{~cm}^{3}$ of soil. It showed a statistical similarity with other inoculum levels. The percentage of egg mass colonization and soil colonization was significantly influenced by all tested doses of bio-agents as well as inoculum levels of nematode. The highest percentage of egg mass colonization and soil colonization was recorded when tested with the highest dose $\left(1 \times 10^{6} \mathrm{CFU} / \mathrm{g}\right.$ soil $)$ of $P$. lilacinaus. Conversely, the lowest percentage of egg mass colonization and soil colonization were observed at the highest inoculum level (3200 eggs $/ 100 \mathrm{~cm}^{3}$ of soil) of $M$. incognita (Table 1 ). The results of the present experiment indicated that the application of $P$. lilacinum PLSAU-1 suppressed root-knot and increased plant growth parameters.

\section{Dose-response relationship}

Two-factor analysis for the plant growth characters (shoot fresh weight, length; root fresh weight, length) showed significant effects on the inoculum level and rates, applied on the brinjal plant. Among the four doses of $P$. lilacinum PLSAU- 1 , the rate of $\left(1 \times 10^{6} \mathrm{CFU} / \mathrm{g}\right.$ soil $)$ enhanced plant growth characters over 400 to 3200 eggs per $100 \mathrm{~cm}^{3}$ soil inoculum level of $M$. incognita than the untreated inoculated control (Table 2).

The major findings of this study revealed that $P$. lilacinum controlled the root-knot nematode and $M$. incognita efficiently increased the plant growth characters. To find out the appropriate dose of P. lilacinum PLSAU-1 against various levels of nematode damage, four fungal doses including $0,1 \times 10^{5}, 5 \times 10^{5}$, and $1 \times 10^{6} \mathrm{CFU} / \mathrm{g}$ soil were applied. Among the different fungal doses, the identified optimum fungal dose was $1 \times 10^{6} \mathrm{CFU} / \mathrm{g}$ soil, where the highest nematode suppression and improved plant growth was recorded (Table 2). Its existence in the rhizosphere of roots at the penetration time might decrease the number of juveniles that could entrance the roots. This finding is in agreement with Holland et al. (1999) who quantified that P. lilacinum colonized the root and protected its surface from root-knot nematode attacks. It correspondingly reduced the number of viable eggs and juveniles of the second generation during the experimental period. These results confirm the findings of Kiewnick and Sikora (2006). They reported that a single pre-plant application at a concentration of $\left(1 \times 10^{6}\right.$ $\mathrm{CFU} / \mathrm{g}$ soil) was needed for sufficient biocontrol of root-knot nematode of $M$. incognita in tomato. In the present study, a significant increase in plant shoots and root length, fresh weight of shoots, and roots was observed by using all doses of P. lilacinum PLSAU-1 compared to untreated control and nematode-inoculated control. Improved character of plant growth by application of P. lilacinum for controlling root-knot nematodes was also reported earlier (Al-Raddad 1995). They tested the effects of Glomus mosseae and P. lilacinum on $M$. javanica of tomato in a greenhouse experiment. The highest root and shoot length, and fresh and dry weight of root and shoot were achieved when the plants were inoculated by $P$. lilacinum to control root-knot nematode. Khan et al. (2012) reported that an enhancement in growth and yield of brinjal with biocontrol agents Pochonia chlamydosporia, P. lilacinum, and Trichoderma harzianum owing to suppress gall formation and egg masses. The result of the present study revealed that the brinjal plants inoculated with 3200 eggs of M. incognita showed a significant reduction in shoot and root length, and fresh weight of shoot and root. Reduced plant growth characters by the inoculation of $M$. incognita were also reported previously by (Ganaie and Khan 2010). The bio-agent significantly reduced the multiplication rate of $M$. incognita than the control. It proved the potentiality of $P$. lilacinum PLSAU-1 as a biocontrol agent against $M$. incognita.

All four doses of P. lilacinum PLSAU-1 were tested, and the lowest gall index development, number of egg masses per root, total nematode population, and reproduction factor were found at 400 and 800 eggs per $\left(100 \mathrm{~cm}^{3}\right.$ soil). For all combination effect of doses and inoculum level, the highest gall index, number of egg masses per root, total nematode population, and reproduction factor were resulted in combination of $\left(1 \times 10^{5} \mathrm{CFU} / \mathrm{g}\right.$ soil $)$ dose of P. lilacinum PLSAU- 1 and 3200 eggs per $\left(100 \mathrm{~cm}^{3}\right.$ of soil) inoculum level of $M$. incognita. At all the inoculum levels, the gall index, number of egg masses per root, total nematode population, and reproduction factor were significantly reduced by the application of $\left(1 \times 10^{6} \mathrm{CFU} / \mathrm{g}\right.$ soil $)$ of $P$. lilacinum PLSAU-1 than the control. However, the maximum reduction of gall index (72\%) and number of egg masses 


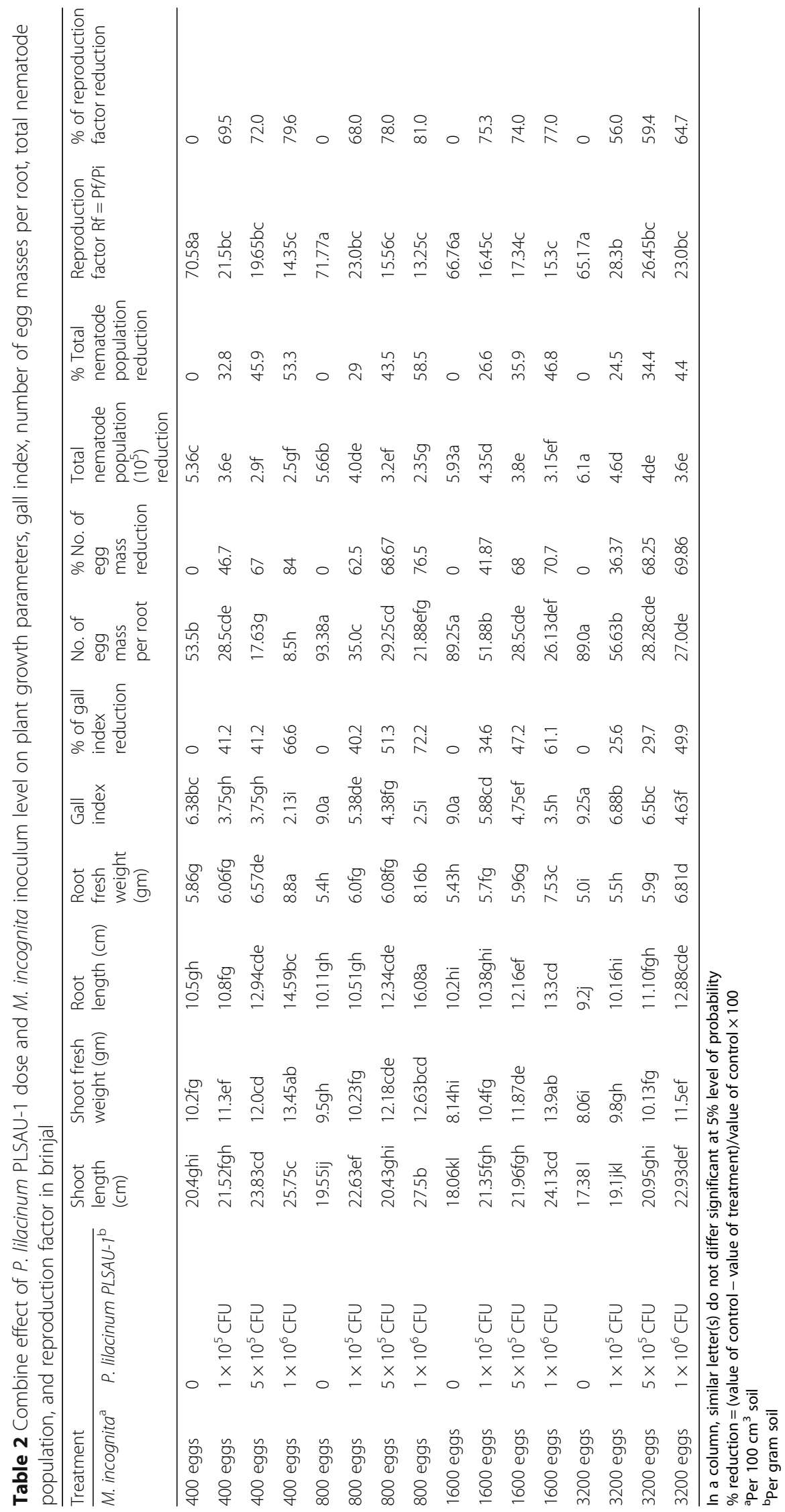


per root (84\%) was recorded at the dose of $1 \times 10^{6} \mathrm{CFU} /$ g soil of $P$. lilacinum PLSAU-1 against 800 and 400 eggs per $100 \mathrm{~cm}^{3}$ of soil inoculum level, respectively. In this experiment, it revealed a significant interaction between the dose of P. lilacinum PLSAU-1 applied to soil and the inoculum level for the parameters of gall index and number of egg masses per root. A similar effect was demonstrated by Kiewnick et al. (2011), and they reported a strong reduction in the galling index and the number of egg masses per root system after PL251 soil treatment at $2 \times 10^{5} \mathrm{CFU} / \mathrm{g}$ soil at inoculum density up to 800 eggs $/ 100 \mathrm{~cm}^{3}$ of soil. This result also was confirmed by Aminuzzaman et al. (2018) who mentioned that the root galling index and the final nematode population decreased up to 55.6 and $66.9 \%$ for brinjal. In addition, the significant reduction of nematode population $(58.5 \%)$ was also observed by the same dose against 800 eggs per $\left(100 \mathrm{~cm}^{3}\right.$ of soil) (Table 2). In case of reproduction factor, $81 \%$ reduction was found at the $1 \times$ $10^{6} \mathrm{CFU} / \mathrm{g}$ soil dose of P. lilacinum PLSAU-1, when pot soil was inoculated by 800 inoculum level per $100 \mathrm{~cm}^{3}$, which was statistically similar to 400 and 1600 inoculum levels, respectively (Table 2). This study indicated that the reduction of $M$. incognita per plant was depended on the doses of $P$. lilacinum PLSAU-1. This result is consistent with the results of Kalele et al. (2010) who reported that the pre-planting soil treatment, with the highest dose $(0.4 \mathrm{~g} / 10 \mathrm{~L}$ soil) reduced 69 and $73 \%$ of nematode population in the roots and soil, respectively, than the inoculated control in a tomato plant.

The colonization increased with the increase of a dose of P. lilacinum PLSAU-1 at all the inoculum levels. The highest percentage of egg mass colonization was recorded in $1 \times 10^{6} \mathrm{CFU} / \mathrm{g}$ soil of $P$. lilacinum PLSAU-1 against 1600 eggs per $100 \mathrm{~cm}^{3}$ inoculum level, and the highest soil colonization was found at the same doses of bio-agent over 800 eggs per $100 \mathrm{~cm}^{3}$ inoculum level of M. incognita (Fig. 1a, b).

The results of the present study demonstrated that the percentage of egg masses colonized by $P$. lilacinum PLSAU-1 directly influenced by the fungal density in the soil. This result consistent with the result of Carneiro and Cayrol (1991) who reported that the number of colonized egg masses and the number of non-viable eggs increased with the increase of $P$. lilacinum density, and the fungus was most effective at a density of $10^{6}$ spores/ $\mathrm{g}$ of soil on banana. The P. lilacinum PLSAU-1 was isolated from soil after 2 months of application, which indicated that the fungus survived throughout the growing season and it was compatible with the environmental conditions. Although the empirical result showed that the CFUs were lower than those added at the beginning of the experiment. The decline in CFU numbers, 2-3 months, after the initial application was also reported by several researchers (Kiewnick and Sikora 2003). They revealed that the persistence of entomopathogenic fungi in soil and the relocation of conidia from the superficial to deeper layers are dependent on the presence of antagonistic organisms on the soil properties This result also validated by Rumbos and Kiewnick (2006). They found the decline in fungal densities (CFU numbers) compared to initial densities ranged from 72.3 to $83.8 \%$ in the first and in the second experiment in a tomato plant, where they inoculated $2 \times 10^{6} \mathrm{CFU} / \mathrm{g}$ of dry soil.
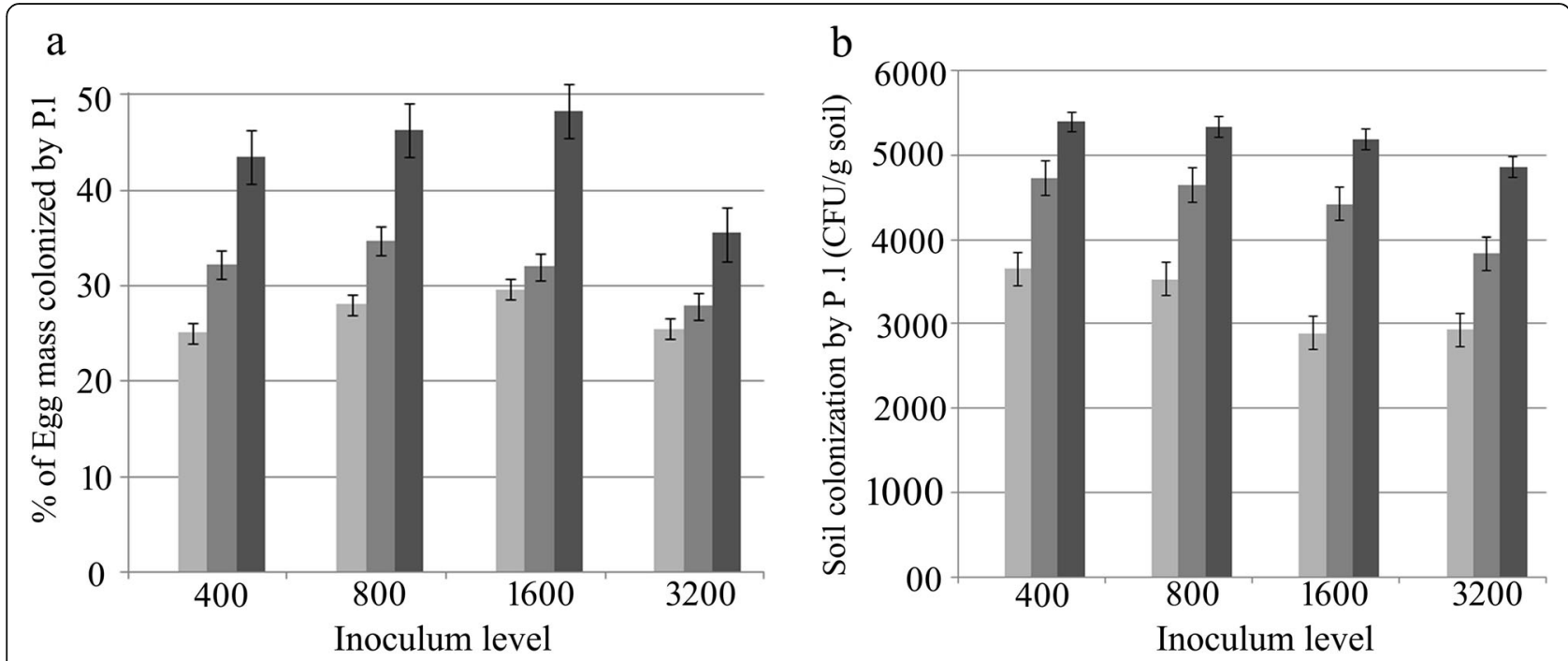

Doses of P. lilacinum $\square 1 \times 10^{5} \mathrm{CFU} / \mathrm{g}$ soil

$5 \times 10^{5} \mathrm{CFU} / \mathrm{g}$ soil

$1 \times 10^{6} \mathrm{CFU} / \mathrm{g}$ soil

Fig. 1 Dose-response relationship of M. incognita and P. lilacinum PLSAU-1 on a percentage of egg mass colonization and $\mathbf{b}$ colonization of fungus/g soil in brinjal 


\section{Conclusion}

The study demonstrated the effects of a dose of $P$. lilacinum PLSAU-1 to suppress root-knot ( $M$. incognita) damage in infected brinjal roots. The key findings of the present were the strong relationship between doses of bio-agent and inoculum level of the pest. This study suggests that high $\left(1 \times 10^{6} \mathrm{CFU} / \mathrm{g}\right.$ soil $)$ dose of $P$. lilacinum PLSAU-1 is necessary for successful control of root-knot nematode $M$. incognita for all tested inoculum level. However, further research is needed to estimate the interactions between inoculum level of $M$. incognita, host plant response, and fungus dose to build up an effective dose-response replica for biocontrol fungus.

\section{Acknowledgements}

We thank to the anonymous reviewers for their kind review and valuable suggestions to improve the earlier version of this manuscript. This research work was supported by the International Foundation for Science, Stockholm, Sweden, [Research Grant Agreement No C/4917-1] and TWAS (The World Academy of Sciences for the advancement of Science in developing countries) [Research Grant No.: 13-246 RG/BIO/AS_/UNESCO FR: 3240277693].

\section{Funding}

There are no funding sources for this manuscript.

\section{Availability of data and materials}

The data and material of this manuscript are available.

\section{Authors' contributions}

The first author (MSS) of this manuscript performed the experiments of this study and wrote the introduction, methodology, and results parts. The second author (FMA) wrote the discussion and conclusion parts. The third author (MEH) completed the analysis part. All authors read and approved the final manuscript.

\section{Ethics approval and consent to participate}

This article does not contain any studies with human participants or animals.

\section{Consent for publication}

The manuscript has not been published in completely or in part elsewhere.

\section{Competing interests}

The authors declare that they have no competing interests.

\section{Publisher's Note}

Springer Nature remains neutral with regard to jurisdictional claims in published maps and institutional affiliations.

\section{Author details}

${ }^{1}$ College of Plant Science and Technology, Huazhong Agricultural University, Shizishan Street-1, Wuhan 430070, Hubei, China. ${ }^{2}$ Department of Plant Pathology, Sher-e-Bangla Agricultural University, Sher-e-Bangla Nagar, Dhaka 1207, Bangladesh. ${ }^{3}$ State Key Laboratory of Information Engineering in Surveying, Mapping and Remote Sensing, Wuhan University, 129 Luoyu Road, Wuhan 430079, Hubei, China.

Received: 13 August 2018 Accepted: 1 April 2019

Published online: 30 April 2019

\section{References}

Abdelnabby H, Mohamed H, Aly HA (2011) Nematode-antagonistic compounds from certain bacterial species. Egypt J Biol Pest Control 21:209-217

Al-Raddad AM (1995) Interaction of Glomus mosseae and Paecilomyces lilacinus on Meloidogyne javanica of tomato. Mycorrhiza 5:233-236

Aminuzzaman F, Jahan S, Shammi J, Mitu A, Liu X (2018) Isolation and screening of fungi associated with eggs and females of root-knot nematodes and their biocontrol potential against Meloidogyne incognita in Bangladesh. Arch Phytopathol Plant Protect 51:288-308

Bari M (2001) Biological control of soil borne diseases of vegetables. Contract research project plant pathology division. Bangladesh Agril res Inst, Joydevpur, Gazipur, pp 21-49

Bridge J, Page S (1980) Estimation of root-knot nematode infestation levels on roots using a rating chart. Int J Pest Manage 26:296-298

Carneiro R, Cayrol J-C (1991) Relationship between inoculum density of the nematophagous fungus Paecilomyces lilacinus and control of Meloidogyne arenaria on tomato. Revue Nematologie 14:629-634

Charegani H, Majzoob S, Hamzehzarghani H, Karegar-Bide A (2012) Effect of various initial population densities of two species of Meloidogyne on growth of tomato and cucumber in greenhouse. Nematol Mediterr 40:129-134

Contreras-Cornejo HA, Macías-Rodríguez L, Cortés-Penagos C, López-Bucio J (2009) Trichoderma virens, a plant beneficial fungus, enhances biomass production and promotes lateral root growth through an auxin-dependent mechanism in Arabidopsis. Plant Physiol 149:1579-1592

Davis RF, Earl HJ, Timper P (2003) Interaction of root-knot nematode stress and water stress in cotton University of Georgia cotton research and extension report, pp 312-315

Ganaie MA, Khan TA (2010) Biological potential of Paecilomyces lilacinus on pathogenesis of Meloidogyne javanica infecting tomato plant. Eur J Appl Sci 2:80-84

Hartman K, Sasser J (eds) (1985) Identification of Meloidogyne species on the basis of differential host test and perineal-pattern morphology vol 2. An advanced treatise on Meloidogyne. North Carolina State University/USAID, Raleigh

Holland RJ, Williams KL, Khan A (1999) Infection of Meloidogyne javanica by Paecilomyces lilacinus. Nematology 1:131-139

Houbraken J, Verweij PE, Rijs AJ, Borman AM, Samson RA (2010) Identification of Paecilomyces variotii in clinical samples and settings. J Clin Microbiol 48:27542761

Huang WK, Sun JH, Cui JK, Wang GF, Kong LA, Peng H, Chen SL, Peng DL (2014) Efficacy evaluation of fungus Syncephalastrum racemosum and nematicide avermectin against the root-knot nematode Meloidogyne incognita on cucumber. PLoS One 9:1-6. https://doi.org/10.1371/journal.pone.0089717

Hussey R, Barker K (1973) Comparison of methods for collecting inocula of Meloidogyne spp., including a new technique. Plant Dis Reporter 57:1025-1028

Johnson LF, Curl EA (1972) Methods for research on the ecology of soil-borne plant pathogens. Burgess Publishing Company, Minneapolis

Kalele D, Affokpon A, Coosemans J, Kimenju J (2010) Suppression of root-knot nematodes in tomato and cucumber using biological control agents. Afr J Hortic Sci 3:72-80

Khan MR, Mohiddin FA, Ejaz MN, Khan MM (2012) Management of root-knot disease in eggplant through the application of biocontrol fungi and dry neem leaves. Turk J Biol 36:161-169

Kiewnick S, Neumann S, Sikora R, Frey J (2011) Effect of Meloidogyne incognita inoculum density and application rate of Paecilomyces lilacinus strain 251 on biocontrol efficacy and colonization of egg masses analyzed by real-time quantitative PCR. Phytopathology 101:105-112

Kiewnick S, Sikora R (2003) Optimizing the efficacy of Paecilomyces lilacinus (strain 251) for the control of root-knot nematodes. Commun Agric Appl Biol Sci 69: 373-380

Kiewnick S, Sikora R (2006) Biological control of the root-knot nematode Meloidogyne incognita by Paecilomyces lilacinus strain 251. Biol Control 38:179-187

Meherunnahar M, Paul D (2009) Bt brinjal: introducing genetically modified brinjal (eggplant/aubergine) in Bangladesh Development Research Working Paper Series. Bangladesh Development Research Center (BDRC), Bangladesh, pp 1-14 https://core.ac.uk/download/pdf/6555450.pdf

Osman HA, Ameen HH, Mohamed M, El-Mohamedy R, Elkelany US (2018) Field control of Meloidogyne incognita and root rot disease infecting eggplant using nematicide, fertilizers, and microbial agents. Egypt J Biol Pest Control 28:1-6 https://doi.org/10.1186/s41938-018-0044-1

Rashid M (2000) A guidebook of plant pathology. Dept of Plant Pathology HSTU, Dinajpur, p 58

Rumbos Cl, Kiewnick S (2006) Effect of plant species on persistence of Paecilomyces lilacinus strain 251 in soil and on root colonization by the fungus. Plant Soil 283:25-31

Saikia SK, Tiwari S, Pandey R (2013) Rhizospheric biological weapons for growth enhancement and Meloidogyne incognita management in Withania somnifera cv. Poshita. Biol Control 65:225-234 
Usman A, Siddiqui M (2012) Effect of some fungal strains for the management of root-knot nematode (Meloidogyne incognita) on eggplant (Solanum melongena). J Agric Technol 8:213-218

Whitehead A, Hemming J (1965) A comparison of some quantitative methods of extracting small vermiform nematodes from soil. Ann Appl Biol 55:25-38

Yang F, Abdelnabby H, Xiao Y (2015a) A mutant of the nematophagous fungus Paecilomyces lilacinus (Thom) is a novel biocontrol agent for Sclerotinia sclerotiorum. Microb Pathog 89:169-176

Yang F, Abdelnabby H, Xiao Y (2015b) The role of a phospholipase (PLD) in virulence of Purpureocillium lilacinum (Paecilomyces lilacinum). Microb Pathog 85:11-20

Submit your manuscript to a SpringerOpen ${ }^{\circ}$ journal and benefit from:

- Convenient online submission

- Rigorous peer review

- Open access: articles freely available online

- High visibility within the field

- Retaining the copyright to your article

Submit your next manuscript at $\boldsymbol{\nabla}$ springeropen.com 